\title{
The environmental hypersensitivity symptom inventory: metric properties and normative data from a population-based study
}

\author{
Steven Nordin ${ }^{1 *}$, Eva Palmquist ${ }^{1}$, Anna-Sara Claeson ${ }^{1}$ and Berndt Stenberg ${ }^{2}$
}

\begin{abstract}
Background: High concomitant intolerance attributed to odorous/pungent chemicals, certain buildings, electromagnetic fields (EMF), and everyday sounds calls for a questionnaire instrument that can assess symptom prevalence in various environmental intolerances. The Environmental Hypersensitivity Symptom Inventory (EHSI) was therefore developed and metrically evaluated, and normative data were established. The EHSI consists of 34 symptom items, requires limited time to respond to, and provides a detailed and broad description of the individual's symptomology.
\end{abstract}

Methods: Data from 3406 individuals who took part in the Västerbotten Environmental Health Study were used. The participants constitute a random sample of inhabitants in the county of Västerbotten in Sweden, aged 18 to 79 years, stratified for age and gender.

Results: Exploratory factor analysis identified five significant factors: airway symptoms ( 9 items; Kuder-Richardson Formula 20 coefficient, KR-20, of internal consistency $=0.74$ ), skin and eye symptoms ( 6 items; KR-20 $=0.60$ ), cardiac, dizziness and nausea symptoms ( 4 items; KR-20 $=0.55$ ), head-related and gastrointestinal symptoms ( 5 items; $K R-20=0.55$ ), and cognitive and affective symptoms (10 items; KR-20 $=0.80$ ). The KR-20 was 0.85 for the entire 34-item EHSI. Symptom prevalence rates in percentage for having the specific symptoms every week over the preceding three months constitute normative data.

Conclusions: The EHSI can be recommended for assessment of symptom prevalence in various types of environmental hypersensitivity, and with the advantage of comparing prevalence rates with normality.

Keywords: Chemical intolerance, Electromagnetic fields, Hyperacusis, Idiopathic environmental intolerance, Prevalence, Sick building syndrome

\section{Background}

Health symptoms attributed to environmental agents are an extensive occupational and public health problem. Apart from toxic and allergenic substances, symptoms are commonly attributed to chemicals and biological materials (e.g., mold) that generate odor and sensory irritation (e.g., pungency), to electrical equipment that generate electromagnetic fields (EMF), and to mechanical phenomena that generate sound. Health effects of exposure to strong EMF are well documented, and such exposure is controlled by regulations and guidelines [1].

\footnotetext{
* Correspondence: steven.nordin@psy.umu.se

'Department of Psychology, Umeå University, Umeå SE-90187, Sweden Full list of author information is available at the end of the article
}

However, there is no existing evidence for health effects from low-level EMF exposure. Instead there is evidence for a nocebo effect in triggering acute health effects [2-4]. Nevertheless, health problems evoked in the presence of electrical equipment is a concern.

Clinical diagnoses for these environmental intolerances (EI) include multiple chemical sensitivity (MCS) [5], nonspecific building-related symptoms (sick building syndrome) [6], idiopathic environmental intolerance attributed to electromagnetic fields (IEI-EMF) [7], and sound sensitivity (hyperacusis) [8]. As many as $6.3 \%$ of a general Swedish population report having a physician-based diagnosis of at least one of these four intolerances, and $21.6 \%$ report an intolerance (not necessarily

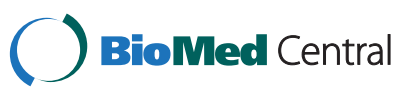


diagnosed) to at least one of the environmental factors odorous/pungent chemicals, certain buildings, EMF, and everyday sounds [9].

Apart from general symptoms (e.g., fatigue and headache) that are common in these EI, certain symptoms seem to be more common in certain types of intolerance. For example, airway symptoms are common in intolerance to odorous/pungent chemicals [10], eye, upper respiratory and skin symptoms among nonspecific building-related symptoms [11], skin symptoms in intolerance attributed to EMF [12], and emotional symptoms and concentration difficulties in sound sensitivity [13]. Regarding EMF, skin symptoms dominate among those who attribute their symptoms to computer screens, fluorescent lamps and television sets, whereas those who attribute their symptoms to EMF in general have a more cognitive and emotional symptom picture $[14,15]$. The symptom picture varies within intolerances in general, and there is overlap between intolerances.

Studies of quality of life in EI have mostly been focused on individuals with severe MCS [16-20], with exception of sound sensitivity [21]. The impact on quality of life is predominantly manifested as not having access to society, and having difficulties keeping a job and maintaining social relations. Hence, in addition to health symptoms that per se are bothersome, attempts to avoid the symptoms by avoiding the environmental exposure results in isolation for the afflicted individual. Indeed, avoidance of the environmental exposure is the most commonly reported coping strategy in MCS [22], and is common also in symptom-attribution to EMF [23] and sounds [13].

Self-reports are important for diagnosing EI due to the lack of objective markers that are generally agreed on. In this context information on the afflicted individual's symptomology is valuable, which also may contribute to the understanding of possible underlying mechanisms. For example, a symptom picture of predominantly airway symptoms may possibly indicate $\mathrm{C}$-fiber hypersensitivity as in sensory hyperreactivity [24], whereas a picture of predominantly cognitive and affective symptoms may indicate an anxiety and stress-related condition [25].

Questionnaire instruments have been developed and metrically evaluated for assessment of specific symptoms in certain types of EI. These include the Quick Environmental Exposure and Sensitivity Inventory [26] and the Idiopathic Environmental Intolerance Symptom Inventory (IEISI) [10] for intolerance to odorous/pungent chemicals, and the MM-questionnaires for nonspecific building-related symptoms [27]. However, there is no documentation of metrically evaluated instruments for specific symptoms attributed to exposure to EMF or everyday sounds. Studies show that concomitant intolerance attributed to odorous/pungent chemicals, certain buildings, EMF, and sounds is common $[9,12,28]$. This motivates simultaneous investigation of these intolerances, which requests a questionnaire instrument that includes relevant symptoms in all these intolerances.

An objective of the current study was to develop and psychometrically evaluate a questionnaire instrument, referred to as the Environmental Hypersensitivity Symptom Inventory (EHSI), for asessment of symtomology in persons with symptoms attributed to odorous/pungent chemicals, certain buildings, EMF, and everyday sounds. The EHSI consists of 34 symptom items, requires limited time to respond to (about $5 \mathrm{~min}$ ), yet it provides a detailed and broad description of the individual's symptomology. The metric evaluation included investigation of dimensionality (factor structure) and reliability (internal consistency). The dimensionality was assessed with factor analysis to accomplish appropriate symptom categories. Thus, it is useful to group the symptoms into appropriate categories to enhance the responders' evaluation of their symptom prevalence and the administrator's interpretation of symptom pattern in the responses.

Another objective was to establish normative data for the EHSI. In addition to normative data for the general population, reference data were provided for combinations of specific age groups (young, middle-aged and elderly adults) and gender. These data referred to having had the specific symptom on a weekly basis over the preceding three months.

There can be a large difference in symptomology between individuals with EI. This suggests that a questionnaire-based instrument aimed at providing a detailed yet broad description of the individual's symptom picture should provide the respondent with the possibility to also report symptoms that are not specifically listed in the questionnaire. The EHSI was therefore designed to also include open-ended questions about additional symptoms pertaining to certain symptom categories as well as to symptoms pertaining to additional, unspecified categories. The objectives of this study were addressed by means of data from a population-based study, the Västerbotten Environmental Health Study.

\section{Methods}

\section{Population and sample}

The Västerbotten Environmental Health Study is an embracing name for different investigations on the same general population regarding various forms of environmental hypersensitivity in Sweden. The study population, inhabitants in the county of Västerbotten in Northern Sweden, has an age and gender distribution that is very similar to that of Sweden in general [29]. A random sample, drawn from the municipal register, of 8600 individuals aged 18 to 79 years was invited to 
participate. The sample was stratified for age and gender according to the following age strata: 18-29, 30-39, 40$49,50-59,60-69$, and 70-79 years. Of the 8600 individuals, 8520 could be reached, among whom 3406 (40.0\%) agreed to participate. Age and gender distributions for the responders are given in Table 1 . The sample is described in Table 2 with respect to demographics, smoking, and health conditions of relevance to symptomology in EI.

\section{The environmental hypersensitivity symptom inventory}

The EHSI is to a large extent based on the IEISI that was developed for assessment of symptom prevalence attributed specifically to odorous/pungent chemicals [10]. The 27 specific symptoms in the IEISI were those reported by at least $20 \%$ of a sample with moderate to severe chemical intolerance. Many of these 27 symptoms are also commonly found in nonspecific building-related symptom [6,30], IEI-EMF [12,31,32], and sound sensitivity [13]. However, certain modifications and additions to the IEISI were made to better cover the symptomology of intolerance to certain buildings, EMF, and sounds. Thus, "skin irritation/redness" was replaced with the four items "facial itching/stinging/tightness/heat", "facial redness", "dry facial skin", and "body itching"; and "head fullness/pressure" was replaced with the two items "head fullness" and "head pressure". Furthermore, "nasal mucosa irritation/dryness", "dry eyes", and "general discomfort" were added. In total, the EHSI consists of 34 specific symptoms.

Open-ended questions about additional symptoms pertaining to the symptom categories as well as to symptoms pertaining to additional, unspecified categories are also included in the EHSI. Since the likelihood of remembering to report a certain condition increases when that condition is provided to the respondent [33], examples of additional symptoms are given after each open-ended question in the EHSI. These examples were adopted from the IEISI. The final version of the EHSI is presented in Figure 1.

Table 1 Numbers of responders (and response percentages) across age and gender strata

\begin{tabular}{lcc}
\hline Age strata (years) & Women & Men \\
\hline $18-29$ & $307(32.7 \%)$ & $179(17.7 \%)$ \\
$30-39$ & $266(40.9 \%)$ & $177(25.2 \%)$ \\
$40-49$ & $288(40.7 \%)$ & $230(31.3 \%)$ \\
$50-59$ & $367(51.0 \%)$ & $295(39.7 \%)$ \\
$60-69$ & $405(58.6 \%)$ & $356(50.7 \%)$ \\
$70-79$ & $265(53.8 \%)$ & $271(63.9 \%)$ \\
$18-79$ & $1898(45.2 \%)$ & $1508(34.9 \%)$ \\
\hline
\end{tabular}

Table 2 Sample characteristics $(n=3406)$

\begin{tabular}{|c|c|}
\hline Age, mean years (SD) & $51.2(16.8)$ \\
\hline Women/men, n (\%) & 1898/1508 (55.7/44.3) \\
\hline \multicolumn{2}{|l|}{ Education (highest), n (\%) } \\
\hline Primary school & $823(24.5)$ \\
\hline High school & $1137(33.8)$ \\
\hline University & $1405(41.8)$ \\
\hline Smoker, n (\%) & $298(8.8)$ \\
\hline \multicolumn{2}{|l|}{ General health status, n (\%) } \\
\hline Very good or excellent & $1349(40.0)$ \\
\hline Good & $1152(34.2)$ \\
\hline Somewhat good or poor & $868(25.8)$ \\
\hline \multicolumn{2}{|l|}{ Diagnosis ${ }^{1}$, n (\%) } \\
\hline Hypertension & $838(24.6)$ \\
\hline Diabetes & $186(5.5)$ \\
\hline Rheumatic disease & $147(4.3)$ \\
\hline Disease in back, joints or muscles & $492(14.4)$ \\
\hline Multiple chemical sensitivity & $107(3.1)$ \\
\hline Nonspecific building-related symptoms & $47(1.4)$ \\
\hline IEI-EMF ${ }^{2}$ & $15(0.4)$ \\
\hline Sound sensitivity & $96(2.8)$ \\
\hline Asthma due to allergy & $164(4.8)$ \\
\hline Asthma other than allergy & $129(3.8)$ \\
\hline Allergic rhinitis & $298(8.7)$ \\
\hline Atopic dermatatis & $88(2.6)$ \\
\hline Migraine & $151(4.4)$ \\
\hline Generaliserad anxiety disorder & $32(1.0)$ \\
\hline Depression & $170(5.0)$ \\
\hline
\end{tabular}

${ }^{1}$ Self-report of having been given a diagnosis by a physician.

${ }^{2}$ Idiopathic environmental intolerance attributed to electromagnetic fields.

For the normative data, the frequency and time interval for a symptom to be considered as prevalent was having had the symptom every week over the preceding three months. This was partly based on the fact that this typically is used for the definition for nonspecific building-related symptoms [34], partly due to the threemonth period being long enough to avoid memory effects and short enough to permit efficient follow-up studies after remedial measures have been taken [27].

\section{Procedure}

A questionnaire was used that included the EHSI and questions regarding demographics, smoking, and health conditions (Table 2). The responders were mailed the questionnaire, to be returned by mail with prepaid postage. Non-responders received up to two reminders. All participants responded to the questionnaire during the period March-April, 2010, before the onset of the pollen season in Västerbotten. The study was conducted in 


\section{The Environmental Hypersensitivity Symptom Inventory}

\section{Which of the following symptoms do you commonly experience when exposed to the environmental source to which you are sensitive?}

\author{
Airway symptoms \\ Asthma or wheezing \\ Shortness of breath \\ Nasal congestion / discharge \\ Postnasal drip \\ Excessive mucus production \\ Nasal mucosa irritation / dryness \\ Sneezing \\ Coughing \\ Throat irritation / hoarseness \\ Other airway symptoms (e.g. susceptibility to infections \\ or mucus in lower airways) \\ Describe these other symptoms:
}

Skin and eye symptoms

Facial itching / stinging / tightness / heat

Facial redness

Dry facial skin

Body itching

Eye irritation / burning

Dry eyes

$\square$ Other skin or eye symptoms (e.g. body stinging or watering eyes)

Describe these other symptoms:

\section{Cardiac, dizziness and nausea symptoms}

\section{Heart pounding}

Chest discomfort

Dizziness / lightheadedness

Nausea

$\square$ Other cardiac, dizziness or nausea symptoms (e.g. irregular heart beat or feeling off balance)

Describe these other symptoms:

Figure 1 The environmental hypersensitivity symptom inventory.
Head-related and gastrointestinal symptoms

$\square$ Headache

$\square$ Head pressure

$\square$ Head fullness

$\square$ Abdominal gas

$\square$ Abdominal swelling / bloating

$\square$ Other head-related or gastrointestinal symptoms (e.g. tender face / sinuses or abdominal pain) Describe these other symptoms:

Cognitive and affective symptoms

$\square$ Memory difficulties

$\square$ Concentration difficulties

$\square$ Absent-minded

$\square$ General discomfort

$\square$ Sleep disturbance

$\square$ Fatigue

$\square$ Irritable / edgy

$\square$ Worried

$\square$ Tensed/nervous

$\square$ Depressed

$\square$ Other cognitive or affective symptoms (e.g. difficulties making decisions or loss of motivation) Describe these other symptoms:

\section{Other symptoms}

$\square$ Other symptoms of any kind (e.g. excessive sweating or joint pain) Describe these other symptoms accordance with the Helsinki Declaration and approved by the Umeå Regional Ethics Board. All responders gave their informed consent to participate.
Statistical analysis

An exploratory factor analysis with Promax rotation and Kaiser normalization was conducted to study 
dimensionality of the 34 specific EHSI symptoms for categorization into symptom groups. An oblique factor rotation was chosen since prior studies of environmental hypersensitivity suggest strong commonalities among various types of somatic symptoms [4]. A scree test plot was made to identify the number of factors to be extracted [35]. The Kuder-Richardson Formula 20 coefficient (KR-20), comparable with the Cronbach alpha coefficient, was used for assessing internal consistency. Normative data for symptom prevalence were expressed in percentages among combinations of specific age groups [young (18-34 years), middle-aged (35-54 years), and elderly (55-79 years)] and gender, for the three age groups separately, for gender separately, and for the total sample. Since the response-rate in different age and gender strata varied, weighted prevalence rates for the entire sample were calculated as well. The weights used were calculated based on the inverse of the probability of respondents in each age and gender strata to participate [36].

\section{Results}

\section{Dimensionality of the EHSI}

The factor analysis of the data for the 34 specific symptoms identified nine factors with an eigenvalue above 1. Their eigenvalues were 6.09 (17.90\% explained variance), 2.60 (7.66\%), 1.57 (4.61\%), 1.36 (4.01\%), 1.31 (3.86\%), 1.09 (3.20\%), 1.06 (3.12\%), 1.05 (3.09\%), and 1.01 (2.95\%). However, a scree-test plot suggests only five factors to be extracted (Figure 2; the number of factors preceding the last "elbow"; [35]). The factor loadings of each EHSI item on each of the five factors are presented in Table 3.

The ten items that loaded strongest on Factor 1 can be referred to as cognitive and affective symptoms; the nine items that loaded strongest on Factor 2 can be referred to as airway symptoms; the six items that loaded

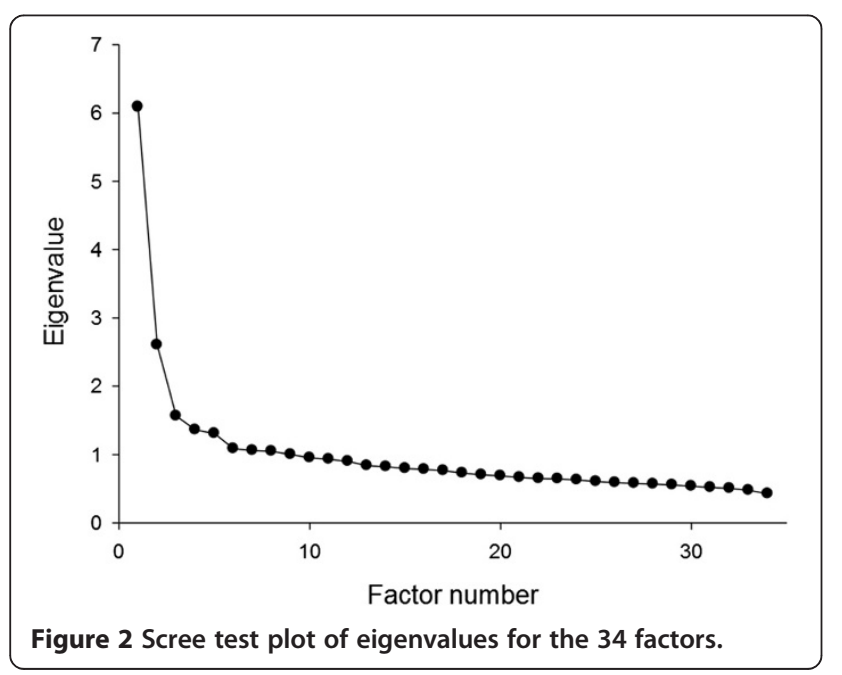

Table 3 Factor loadings with the strongest loading for each symptom item given in bold

\begin{tabular}{|c|c|c|c|c|c|}
\hline & 1 & 2 & 3 & 4 & 5 \\
\hline Concentration difficulties & .695 & .145 & .273 & .216 & .260 \\
\hline Depressed & .667 & .084 & .149 & .235 & .248 \\
\hline Worried & 649 & .072 & .154 & .298 & .239 \\
\hline Tensed/nervous & .644 & .046 & .189 & .317 & .210 \\
\hline Absent-minded & .613 & .159 & .210 & .107 & .223 \\
\hline General discomfort & .607 & .080 & .152 & .428 & .182 \\
\hline Irritable/edgy & .599 & .090 & .170 & .174 & .322 \\
\hline Memory difficulties & .564 & .205 & .263 & .172 & .142 \\
\hline Fatigue & .545 & .142 & .243 & .102 & .466 \\
\hline Sleep disturbance & .402 & .163 & .209 & .101 & .299 \\
\hline Coughing & .119 & .683 & .106 & .240 & .072 \\
\hline Throat irritation/hoarseness & .119 & .665 & .176 & .239 & .122 \\
\hline Shortness of breath & .174 & .656 & .124 & .528 & -.131 \\
\hline Excessive mucus production & .141 & .587 & .196 & .246 & -.057 \\
\hline Postnasal drip & .128 & .564 & .273 & .106 & .137 \\
\hline Nasal congestion/discharge & .133 & .555 & .194 & .059 & .327 \\
\hline Sneezing & .139 & .555 & .175 & .064 & .349 \\
\hline Irritation/dryness of the nasal mucosa & .145 & .497 & .408 & .061 & .236 \\
\hline Asthma or wheezing & .044 & .476 & .093 & .397 & -.253 \\
\hline Facial itching/stinging/tightness/heat & .205 & .184 & .691 & .201 & .076 \\
\hline Facial redness & .221 & .136 & .689 & .134 & .074 \\
\hline Dry facial skin & .259 & .133 & .599 & .057 & .266 \\
\hline Dry eyes & .090 & .238 & .509 & .169 & .213 \\
\hline Body itching & .207 & .197 & .478 & .154 & .147 \\
\hline Eye irritation/burning & .192 & .350 & .460 & .173 & .247 \\
\hline Chest discomfort & .238 & .188 & .143 & .602 & .106 \\
\hline Heart pounding & .264 & .126 & .206 & .567 & .136 \\
\hline Nausea & .270 & .167 & .107 & .493 & .424 \\
\hline Dizziness/lightheadedness & .238 & .159 & .254 & .476 & .313 \\
\hline Abdominal gas & .217 & .167 & .216 & .040 & .581 \\
\hline Abdominal swelling/bloating & .267 & .114 & .220 & .195 & .562 \\
\hline Headache & .273 & .129 & .069 & .173 & .535 \\
\hline Head fullness & .359 & .187 & .215 & .307 & .438 \\
\hline Head pressure & .281 & .078 & .162 & .367 & .399 \\
\hline
\end{tabular}

strongest on Factor 3 can be referred to as skin and eye symptoms; the four items that loaded strongest on Factor 4 can be referred to as cardiac, dizziness and nausea symptoms; and the five items that loaded strongest on Factor 5 can be referred to as head-related and gastrointestinal symptoms.

\section{Reliability and normative data of the EHSI}

The KR-20 coefficient was 0.74 for airway symptoms, 0.60 for skin and eye symptoms, 0.55 for cardiac, 
dizziness and nausea symptoms, 0.55 for head-related and gastrointestinal symptoms, 0.80 for cognitive and affective symptoms, and 0.85 for the entire 34-item EHSI. Normative data are given in Table 4 for prevalence of specific symptoms expressed in percentages of subpopulations who report having each symptom every week over the preceding three months.

\section{Discussion}

An objective of the present study was to develop and psychometrically evaluate a questionnaire-based instrument, the EHSI, for assessment of symptom prevalence in persons with common types of environmental hypersensitivity. The instrument was aimed at requiring limited time to respond to, yet provide a detailed and broad description of the symptomology of the individual or group under study. Although the symtomology was focused on persons who attribute their symptoms to odorous/pungent chemicals, certain buildings, EMF, and sounds, the wide range of symptoms in the EHSI is likely to cover the symtomology of several other types of environmental hypersensitivity, including asthma and allergy.

The evaluation of the EHSI suggests a factor structure of five factors: airway symptoms, skin and eye symptoms, cardiac, dizziness and nausea symptoms, headrelated and gastrointestinal symptoms, and cognitive and affective symptoms. The grouping of the cardiac, dizziness and nausea symptoms can be explained by sympathetic activity such that extensive heart pounding can cause chest discomfort, nausea and dizziness. Grouping of head-related and gastrointestinal symptoms can be referred to both types of symptoms being common psychosomatic symptoms. As would be expected, the head-related and gastrointestinal symptoms were found to load relatively high on the cognitive and affective factor. The outcome from the factor analysis was similar to that reported by Miller and Mitzel [37] and by Andersson and associates [10], also using factor analysis, for those symptoms that were in common between studies.

The internal consistency of the entire EHSI and the symptom category cognitive and affective symptoms can be considered as good, the symptom category airway symptoms can be considered as acceptable, the symptom category skin and eye symptoms can be considered as questionable, and the symptom categories cardiac, dizziness and nausea symptoms, and head-related and gastrointestinal symptoms can be considered as poor. The poor consistency in the latter two symptom categories is likely to be due to these categories having few items in combination with being rather broad. A consequence is that use of a composite measure of cardiac, dizziness and nausea symptoms, and head-related and gastrointestinal symptoms from the EHSI should be supplemented with inspection of whether there is a large variability between the symptoms in this category. The validity of the EHSI was not investigated in this study. One reason for this is that the majority of its symptoms have been validated in a prior study of environmental hypersensitivity [10]. Another reason is the simplicity of assessment with the EHSI: having a specific symptom or not. Thus, the face validity [38] of the EHSI can be considered as good.

Another objective of the study was to provide normative data for various subgroups of age and gender, and for the general adult population. The population-based nature of the Västerbotten Environmental Health Study and the fact that the study population has an age and gender distribution that is very similar to that of Sweden in general [29] enhances the representativeness. However, among the randomly selected individuals only $40 \%$ volunteered, which compromises the representativeness. Research ethical regulations for conducting research in Sweden do not allow asking the selected individuals why they chose not to participate or about certain characteristics they may possess [39]. However, information on age and gender was available for those who declined participation in this study, and the largest proportion of non-responders was found among young men (Table 1). The generally low response rate increases the risk of a selection bias. Thus, the special topic of the study (environmental health) may have attracted, in particular, respondents with health problems attributed to environmental aspects [40], which may have resulted in the prevalence rates being higher than otherwise would have been the case. Comparisons with data from prior Swedish population-based studies do only partly support the notion that the current prevalence rates are too high. Whereas Eriksson and Stenberg [34] reported prevalence rates for adults aged 18-64 years that were generally lower than in the present study, Andersson and Norlén [41] reported rates based on all ages that were generally higher. The generally higher prevalence rates in women than in men (Table 4) accord with typical results on gender differences [42], and the pattern of age-related differences corresponds in general with prior Swedish population-based data for young and middle-aged adults [34].

The applicability of the EHSI is not limited to assessment of having had the specific symptoms every week over the preceding three months, or to assessment of prevalence (yes/no), for which the normative data are valid. The instrument can also be used for assessing the prevalence of symptoms as a direct result of the environmental exposure. Furthermore, the respondent can rate to what extent he/she experiences each symptom. An example of an appropriate rating scale for such a 
Table 4 Percentage reporting having had symptoms every week over the preceding three months, constituting normative data

\begin{tabular}{|c|c|c|c|c|c|c|c|c|c|c|c|c|c|}
\hline & $\begin{array}{l}\text { Young } \\
\text { women } \\
(n=441)\end{array}$ & $\begin{array}{c}\text { Young } \\
\text { men } \\
(n=265)\end{array}$ & $\begin{array}{c}\text { Middle- } \\
\text { aged } \\
\text { women } \\
(n=597)\end{array}$ & $\begin{array}{c}\text { Middle- } \\
\text { aged } \\
\text { men } \\
(\mathrm{n}=455)\end{array}$ & $\begin{array}{l}\text { Elderly } \\
\text { women } \\
(\mathrm{n}=860)\end{array}$ & $\begin{array}{c}\text { Elderly } \\
\text { men } \\
(n=788)\end{array}$ & $\begin{array}{c}\text { All } \\
\text { young } \\
(n=706)\end{array}$ & $\begin{array}{c}\text { All } \\
\text { middle- } \\
\text { aged } \\
(\mathrm{n}=1052)\end{array}$ & $\begin{array}{c}\text { All } \\
\text { elderly } \\
(n=1648)\end{array}$ & $\begin{array}{c}\text { All } \\
\text { women } \\
(n=1898)\end{array}$ & $\begin{array}{c}\text { All } \\
\text { men } \\
(n=1508)\end{array}$ & $\begin{array}{c}\text { Total } \\
\text { sample } \\
\text { unweighted } \\
(\mathrm{n}=3406)\end{array}$ & $\begin{array}{c}\text { Total } \\
\text { sample } \\
\text { weighted } \\
(\mathrm{n}=3406) \\
\end{array}$ \\
\hline \multicolumn{14}{|l|}{ Airway symptoms } \\
\hline Asthma or wheezing & 5.0 & 6.0 & 6.9 & 7.7 & 11.0 & 11.4 & 5.4 & 7.2 & 11.2 & 8.3 & 9.4 & 8.8 & 8.1 \\
\hline Shortness of breath & 7.7 & 6.4 & 8.2 & 7.5 & 11.6 & 12.2 & 7.2 & 7.9 & 11.9 & 9.6 & 9.7 & 9.7 & 9.0 \\
\hline Nasal congestion/discharge & 28.1 & 21.9 & 25.0 & 21.8 & 25.1 & 29.2 & 25.8 & 23.6 & 27.1 & 25.8 & 25.7 & 25.7 & 25.0 \\
\hline Postnasal drip & 8.4 & 6.8 & 9.0 & 6.8 & 12.2 & 9.4 & 7.8 & 8.1 & 10.8 & 10.3 & 8.2 & 9.3 & 8.7 \\
\hline Excessive mucus production & 3.4 & 3.8 & 4.2 & 5.7 & 8.1 & 8.8 & 3.5 & 4.8 & 8.4 & 5.8 & 7.0 & 6.3 & 5.7 \\
\hline Nasal mucosa irritation/dryness & 13.8 & 8.7 & 22.8 & 12.5 & 28.8 & 17.8 & 11.9 & 18.3 & 23.5 & 23.4 & 14.6 & 19.5 & 17.3 \\
\hline Sneezing & 27.9 & 20.4 & 24.1 & 23.7 & 30.8 & 26.8 & 25.1 & 24.0 & 28.9 & 28.0 & 24.7 & 26.6 & 25.6 \\
\hline Coughing & 15.4 & 12.5 & 17.3 & 16.0 & 23.3 & 20.8 & 14.3 & 16.7 & 22.1 & 19.5 & 17.9 & 18.8 & 17.4 \\
\hline Throat irritation/hoarseness & 11.6 & 9.8 & 12.7 & 10.8 & 19.8 & 17.1 & 10.9 & 11.9 & 18.5 & 15.6 & 13.9 & 14.9 & 13.8 \\
\hline \multicolumn{14}{|l|}{ Skin and eye symptoms } \\
\hline Facial itching/stinging/tightness/heat & 5.9 & 0.4 & 6.5 & 3.3 & 7.2 & 3.8 & 3.8 & 5.1 & 5.6 & 6.7 & 3.1 & 5.1 & 4.6 \\
\hline Facial redness & 7.0 & 3.0 & 8.2 & 4.2 & 7.2 & 4.1 & 5.5 & 6.5 & 5.7 & 7.5 & 3.9 & 5.9 & 5.5 \\
\hline Dry facial skin & 37.2 & 15.1 & 24.3 & 13.4 & 20.0 & 8.5 & 28.9 & 19.6 & 14.5 & 25.3 & 11.1 & 19.1 & 19.1 \\
\hline Body itching & 14.3 & 5.7 & 14.1 & 13.2 & 14.5 & 12.4 & 11.0 & 13.7 & 13.5 & 14.3 & 11.5 & 13.1 & 12.2 \\
\hline Eye irritation/burning & 8.6 & 7.5 & 14.4 & 9.9 & 18.8 & 13.5 & 8.2 & 12.5 & 16.3 & 15.1 & 11.3 & 13.4 & 12.1 \\
\hline Dry eyes & 11.8 & 7.2 & 14.7 & 8.8 & 21.6 & 11.3 & 10.1 & 12.2 & 16.7 & 17.2 & 9.8 & 13.9 & 12.5 \\
\hline \multicolumn{14}{|l|}{$\begin{array}{l}\text { Cardiac, dizziness and } \\
\text { nausea symptoms }\end{array}$} \\
\hline Heart pounding & 8.8 & 1.9 & 8.9 & 6.4 & 12.1 & 7.0 & 6.2 & 7.8 & 9.6 & 10.3 & 5.9 & 8.4 & 7.5 \\
\hline Chest discomfort & 6.8 & 3.4 & 5.4 & 5.3 & 7.6 & 7.4 & 5.5 & 5.3 & 7.5 & 6.7 & 6.0 & 6.4 & 6.0 \\
\hline Dizziness/lightheadedness & 10.9 & 1.5 & 8.9 & 3.3 & 10.6 & 7.6 & 7.4 & 6.5 & 9.2 & 10.1 & 5.2 & 8.0 & 6.9 \\
\hline Nausea & 14.3 & 2.3 & 7.2 & 5.5 & 5.8 & 2.8 & 9.8 & 6.5 & 4.4 & 8.2 & 3.5 & 6.1 & 6.1 \\
\hline \multicolumn{14}{|l|}{$\begin{array}{l}\text { Head-related and } \\
\text { gastrointestinal symptoms }\end{array}$} \\
\hline Headache & 41.0 & 23.8 & 36.3 & 24.0 & 23.1 & 9.9 & 34.6 & 31.0 & 16.8 & 31.5 & 16.6 & 24.9 & 25.9 \\
\hline Head pressure & 10.7 & 3.8 & 9.5 & 5.5 & 4.9 & 2.7 & 8.1 & 7.8 & 3.8 & 7.7 & 3.7 & 5.9 & 6.0 \\
\hline Head fullness & 19.0 & 9.8 & 15.1 & 10.5 & 11.9 & 6.0 & 15.6 & 13.1 & 9.0 & 14.5 & 8.0 & 11.7 & 11.9 \\
\hline Abdominal gas & 44.9 & 32.5 & 37.7 & 37.1 & 37.0 & 30.8 & 40.2 & 37.5 & 34.0 & 39.0 & 33.0 & 36.4 & 36.5 \\
\hline Abdominal swelling/bloating & 29.7 & 7.2 & 21.9 & 11.2 & 17.1 & 8.8 & 21.2 & 17.3 & 13.1 & 21.5 & 9.2 & 16.1 & 15.8 \\
\hline
\end{tabular}


Table 4 Percentage reporting having had symptoms every week over the preceding three months, constituting normative data (Continued)

Cognitive and affective symptoms

\begin{tabular}{|c|c|c|c|c|c|c|c|c|c|c|c|c|c|}
\hline Memory difficulties & 13.4 & 9.8 & 20.3 & 14.1 & 14.8 & 17.1 & 12.0 & 17.6 & 15.9 & 16.2 & 14.9 & 15.6 & 14.7 \\
\hline Concentration difficulties & 24.9 & 16.6 & 22.3 & 16.0 & 13.7 & 8.8 & 21.8 & 19.6 & 11.3 & 19.0 & 12.3 & 16.1 & 16.7 \\
\hline Absent-minded & 33.8 & 23.8 & 25.3 & 15.8 & 15.5 & 12.2 & 30.0 & 21.2 & 13.9 & 22.8 & 15.3 & 19.5 & 20.7 \\
\hline General discomfort & 12.2 & 3.8 & 8.5 & 7.5 & 4.0 & 2.7 & 9.1 & 8.1 & 3.3 & 7.3 & 4.3 & 6.0 & 6.3 \\
\hline Sleep disturbance & 26.1 & 16.6 & 32.3 & 22.6 & 33.6 & 19.5 & 22.5 & 28.1 & 26.9 & 31.5 & 20.0 & 26.4 & 24.9 \\
\hline Fatigue & 62.8 & 41.1 & 55.6 & 39.6 & 38.6 & 25.8 & 54.7 & 48.7 & 32.5 & 49.6 & 32.6 & 42.1 & 43.2 \\
\hline Irritable/edgy & 31.7 & 21.5 & 26.3 & 17.1 & 10.3 & 7.7 & 27.9 & 22.3 & 9.1 & 20.3 & 13.0 & 17.1 & 18.6 \\
\hline Worried & 29.3 & 18.1 & 21.4 & 18.0 & 17.4 & 9.1 & 25.1 & 20.0 & 13.5 & 21.4 & 13.4 & 17.9 & 18.6 \\
\hline Tensed/nervous & 23.4 & 8.3 & 16.2 & 10.8 & 7.0 & 2.7 & 17.7 & 13.9 & 4.9 & 13.7 & 6.1 & 10.3 & 11.1 \\
\hline Depressed & 31.5 & 16.2 & 18.1 & 15.2 & 14.8 & 8.0 & 25.8 & 16.8 & 11.5 & 19.7 & 11.6 & 16.1 & 17.0 \\
\hline
\end{tabular}

Young $=18-34$ years, middle-aged $=35-54$ years, elderly $=55-79$ years. 
purpose is the Environmental Annoyance Scale, which is a category scale with seven semantic descriptors [Not at all (0), a little (1), partly (2), pretty much (3), rather much (4), to a large extent (5), and extremely much (6)], and with ratio-scale properties and good reliability and validity [43].

\section{Conclusions}

The 34-item EHSI for assessment of symptoms in various types of environmental hypersensitivity requires limited time to respond to, yet provides a detailed and broad description of the symptomology, including airway, skin, eye, cardiac, dizziness, nausea, head-related, gastrointestinal, cognitive and affective symptoms. Measures of internal consistency suggest that symptom prevalence can reliably be combined for a composite measure for the entire EHSI and for the symptom categories airway symptoms, skin and eye symptoms, and cognitive and affective symptoms. In contrast, caution should be taken when combining items for the symptom categories cardiac, dizziness and nausea symptoms, and head-related and gastrointestinal symptoms. Normative data for various subgroups of age and gender, and for the general adult population are available for having had the specific symptoms every week over the preceding three months.

\section{Competing interests}

The authors declare that they have no competing interests.

\section{Authors' contributions}

All authors contributed in planning the study. SN and EP organized the data collection. SN drafted the article, and EP, ASC and BS read and approved the final version of the manuscript.

\section{Acknowledgements}

This study was supported by grants from the European territorial cooperation program Botnia-Atlantica, Region Västerbotten (Sweden), and the Regional Council of Ostrobothnia (Finland). We gratefully acknowledge Annika Glader for supervising the TEMA project of which this work was part.

\section{Author details}

'Department of Psychology, Umeå University, Umeå SE-90187, Sweden. ${ }^{2}$ Department of Public Health and Clinical Medicine, Umeå University, Umeå 414 SE-90187, Sweden.

Received: 20 April 2013 Accepted: 27 June 2013 Published: 9 July 2013

\section{References}

1. International Commission on Non-lonizing Radiation Protection: Guidelines for limiting exposure to time-varying electric, magnetic, and electromagnetic fields (up to $300 \mathrm{GHz}$ ). Health Phys 1998, 74:494-522.

2. Rubin GJ, Rosa Nieto-Hernandez R, Wessely S: Idiopathic environmental intolerance attributed to electromagnetic fields (formerly 'electromagnetic hypersensitivity'): an updated systematic review of provocation studies. Bioelectromagnetics 2010, 31:1-11.

3. Szemerszky R, Köteles F, Lihi R, Bárdos G: Polluted places or polluted minds? An experimental sham-exposure study on background psychological factors of symptom formation in 'Idiophatic Environmental Intolerance attributed to electromagnetic fields'. Int J Hyg Environ Health 2010, 213:387-394
4. Witthöft M, Rubin GJ: Are media warnings about the adverse health effects of modern life self-fulfilling? An experimental study on idiopathic environmental intolerance attributed to electromagnetic fields (IEI-EMF). J Psychosom Res 2013, 74:206-212.

5. Labarge AS, McCaffrey RJ: Multiple chemical sensitivity: a review of the theoretical and research literature. Neuropsychological Review 2010, 10:183-211.

6. Hodgson MJ, Addorisio MR: Exposures in indoor environments. In Textbook of Clinical Occupational and Environmental Medicine. 2nd edition. Edited by Rosenstock L, Cullen MR, Brodkin CA, Redlich CA. Philadelphia: Elsevier Saunders; 2005:1133-1142.

7. Genuis SJ, Lipp CT: Electromagnetic hypersensitivity: fact or fiction? Sci Total Environ 2012, 414:103-112.

8. Baguley DM: Hyperacusis. J Royal Soc Med 2003, 96:582-585.

9. Nordin S, Söderholm A, Palmquist E, Andersson L, Claeson A-S, Nordin M: Miljökänslighet: den osynliga folksjukdomen. Ett detektivarbete kring orsakerna till miljörelaterad överkänslighet. In Byggnadsrelaterad ohälsa $i$ Kvarkenregionen - nio delprojekt om miljökänslighet, luftkvalitet och sjuka hus ur ett tvärvetenskapligt perspektiv hälsa. Edited by Osterberg M. Vasa: Novia produktion och publikation; 2012:30-43. Series R: Report no.

10. Andersson MJE, Andersson L, Bende M, Millqvist E, Nordin S: The idiopathic environmental intolerance symptom inventory: development, evaluation and application. J Occup Environ Med 2009, 51:838-847.

11. Edvardsson B, Stenberg B, Bergdahl J, Eriksson N, Lindén G, Widman L: Medical and social prognoses of non-specific building-related symptoms (Sick Building Syndrome): a follow-up study of patients previously referred to hospital. Int Arch Occup Environ Health 2008, 81:805-812.

12. Hillert $L$, Berglind N, Arnetz BB, Bellander T: Prevalence of self-reported hypersensitivity to electric or magnetic fields in a population-based questionnaire survey. Scand J Work Environ Health 2002, 28:33-41.

13. Andersson G, Lindvall N, Hursti T, Carlbring P: Hypersensitvity to sound (hyperacusis): a prevalence study conducted via the internet and post. Int J Audiol 2002, 41:545-54.

14. Bergdahl J, Stenberg B, Eriksson N, Lindén G, Widman L: Coping and selfimage in patients with visual display terminal-related skin symptoms and perceived hypersensitivity to electricity. Int Arch Occup Environ Health 2004, 77:538-542.

15. Johansson A, Nordin S, Heiden M, Sandström M: Symptoms, personality traits, and stress in people with mobile phone-related symptoms and electromagnetic hypersensitivity. J Psychosom Res 2010, 68:37-45.

16. Lipson JG: Multiple chemical sensitivities: stigma and social experiences. Med Anthropol 2004, 18:200-213.

17. Larsson C, Mårtensson L: Experiences of problems in individuals with hypersensitivity to odours and chemicals. J Clin Nurs 2009, 18:737-744

18. Skovbjerg S, Brorson S, Rasmussen A, Johansen JD, Elberling J: Impact of self-reported multiple chemical sensitivity on everyday life: a qualitative study. Scand J Publ Health 2009, 37:621-626.

19. Gibson PR: Of the world but not in it: barriers to community access and education for persons with environmental sensitivities. Health Care Women Int 2010, 31:3-16.

20. Söderholm A, Söderberg A, Nordin S: The experience of living with sensory hyperreactivity: accessibility, financial security and social relationships. Health Care Women Int 2011, 32:686-707.

21. Shepherd D, Welch D, Dirks KN, Mathews R: Exploring the relationship between noise sensitivity, annoyance and health-related quality of life in a sample of adults exposed to environmental noise. Int J Environ Res Publ Health 2010, 7:3579-3594.

22. Nordin M, Andersson L, Nordin S: Coping strategies, social support and responsibility in chemical intolerance. J Clin Nurs 2010, 19:2162-2173.

23. Stenberg B, Bergdahl J, Edvardsson B, Eriksson N, Lindén G, Widman L: Medical and social prognosis for patients with perceived hypersensitivity to electricity and skin symptoms related to the use of visual display terminals. Scand J Work Environ Health 2002, 28:349-357.

24. Millqvist E: Mechanisms of increased airway sensitivity to occupational chemicals and odors. Curr Opin Allergy Clin Immunol 2008, 8:135-139.

25. Fiedler N, Kelly-McNeil K, Ohman-Strickland P, Zhang J, Ottenweller J, Kipen HM: Negative affect and chemical intolerance as risk factors for buildingrelated symptoms: a controlled exposure study. Psychosom Med 2008, 70:254-262

26. Miller CS, Prihoda TJ: The environmental exposure and sensitivity inventory (EESI): a standardized approach for measuring chemical 
intolerances for research and clinical applications. Toxicol Ind Health 1999, 15:370-385

27. Andersson K: Epidemiological approach to indoor air problems. Indoor Air 1998, 4(Suppl):32-39.

28. Carlsson F, Karlsson B, Orbaek P, Österberg K, Östergren PO: Prevalance of annoyance attributed to electrical equipment and smells in a Swedish population, and relationsship with subjective health and daily function. Public Health 2005, 119:568-577.

29. Statistics Sweden: Tables of Sweden's population 2009: 1.3.1 Population by sex, age, marital status by county Dec. 31, 2009 according to the administrative subdivisions of January 1, 2010; 2013. http://www.scb.se/statistik/_publikationer/BE0101_ 2009A01_BR_05_BE0110TAB.pdf.

30. World Health Organization (WHO): Indoor air quality and research. Euro Reports and Studies 103. Geneva: WHO; 1986.

31. Röösli M, Moser M, Baldinini Y, Meier M, Braun-Fahrländer C: Symptoms of ill health ascribed to electromagnetic field exposure: a questionnaire survey. Int J Hyg Environ Health 2004, 207:141-150

32. World Health Organization (WHO): Electromagnetic fields and public health. Fact sheet No 296. Geneva: WHO Media Centre; 2005.

33. Schwarz N: Self-reports: how the questions shape the answers. Am Psychol 1999, 54:93-105.

34. Eriksson NM, Stenberg BGT: Baseline prevalence of symptoms related to indoor environment. Scand J Publ Health 2006, 34:387-396.

35. Cattell RB: The scree test for the number of factors. Multivar Behav Res $1966,1: 245-276$

36. Höfler M, Pfister $\mathrm{H}$, Lieb $\mathrm{R}$, Wittchen $\mathrm{H}-\mathrm{U}$ : The use of weights to account for non-response and drop-out. Soc Psychiatry Psychiatr Epidemiol 2004, 40:291-299.

37. Miller C, Mitzel HC: Chemical sensitivity attributed to pesticide exposure versus remodeling. Arch Environ Health 1995, 50:119-129.

38. Anastasia A: Psychological testing. New York: Macmillan; 1988.

39. Proposition 2007/08:44: Vissa etikprövningsfrägor m.m. http://www. regeringen.se/content/1/c6/09/48/06/b497e80c.pdf.

40. Groves RM, Couper MP, Presser S, Singer E, Tourangeau R, Acosta GP, Nelson L: Experiments in producing nonresponse bias. Publ Opin Quart 2006, 70:720-736.

41. Andersson K, Norlén U: Indoor climate and health effects: The indoor climate in the Swedish housing stock. In Indoor air quality in practice: moisture and cold climate solutions. Edited by Flatheim G, Berg K, Edvardsen K. Oslo: Norwegian Society of Chartered Engineers; 1995:23-28.

42. Gijsbergs van Wijk CMT, Kolk AM: Sex differences in physical symptoms: the contribution of symptom perception theory. Soc Sci Med 1977 45:231-246.

43. Nordin S, Lidén E, Gidlöf-Gunnarsson A: Development and evaluation of a category ratio scale with semantic descriptors: the environmental annoyance scale. Scand J Psychol 2009, 50:93-100.

doi:10.1186/0778-7367-71-18

Cite this article as: Nordin et al.: The environmental hypersensitivity symptom inventory: metric properties and normative data from a population-based study. Archives of Public Health 2013 71:18.

\section{Submit your next manuscript to BioMed Central and take full advantage of:}

- Convenient online submission

- Thorough peer review

- No space constraints or color figure charges

- Immediate publication on acceptance

- Inclusion in PubMed, CAS, Scopus and Google Scholar

- Research which is freely available for redistribution

Submit your manuscript at www.biomedcentral.com/submit 